\title{
Sobre el régimen estético de las artes en Jacques Rancière: heteronomía, sensorium y montaje*
}

\author{
Felipe Larrea \\ U. de Chile \\ larrea.felipe@gmail.com
}

\begin{abstract}
Resumen
Nos proponemos trabajar cierta zona de lo que Jacques Rancière ha pensado como "régimen estético de las artes". A partir de esta comprensión, revisaremos los otros dos regímenes del arte, pero más directamente el régimen representativo, con el cual el estético plantea su ruptura. Para ello, trabajaremos una contraposición directa con la noción de muthos (historia, relato, fábula) que se encuentra en la Poética de Aristóteles y con los "malos entendidos" que vislumbra Rancière sobre la modernidad artística, en particular con lo que se pensó a partir del modernismo y la autonomía estética, que, entre otras cosas, le adjudicó una relevancia decisiva al concepto de montaje.
\end{abstract}

Palabras claves

Muthos, representativo, estética, sensorium, montaje.

\section{On the Aesthetic Regime of the Arts in Jacques Rancière: Heteronomy, Sensorium, and Montage}

\begin{abstract}
We intend to study a certain area of what Jacques Rancière considered an "aesthetic regime of the arts". From this perspective, we will review the other two regimes of art, focusing more specifically on the representative regime, from which the aesthetic regime breaks away. To do so, we will directly compare the notion of muthos (history, story, fable), present in Aristotle's Poetics, with Rancière's idea of "misunderstanding" in artistic modernity, particularly in regards to the influence of modernism and aesthetic autonomy, which granted decisive relevance to the concept of montage.
\end{abstract}

Keywords

Muthos, representative, aesthetic, sensorium, montage.

* Recibido: 14 de marzo de 2016 / Aceptado: 24 de octubre de 2016. 
Felipe Larrea. Sobre el régimen estético de las artes en Jacques Rancière: heteronomía...

\section{Sobre o regime estético das artes em Jacques Rancière: heteronomía, sensório e montagem}

Resumo

Pretendemos trabalhar uma determinada área do que Jacques Rancière propõe como "regime estético das artes." A partir desta compreensão revisaremos os outros dois regimes de arte, mas diretamente o regime representativo, com a qual a estética propõe sua ruptura. Nessa empreitada, trabalharemos uma noção de contraste direto com a noção de muthos (história, relatório, fábula) encontrada na Poética de Aristóteles, por sua vez também contra o "mal-entendido", que se vislumbra em Rancière na arte moderna, principalmente, com o pensado sobre o modernismo e da autonomia estética, que entre outras coisas foi premiado com uma relevância decisiva para o conceito de montagem.

Palavras-chave

Muthos, representativo, estética, sensorium, montagem. 


\section{Introducción}

El pensamiento de Jacques Rancière ha actualizado los debates en torno a las prácticas artísticas contemporáneas y las teorías que se desprenden de ellas en lo que va de siglo XXI. Esto se debe, fundamentalmente, a que ha formulado una singular manera de aproximarse al problema estético; el que ya no podría definirse como un proceder a partir de obras o prácticas puntuales del arte, entendido éste como un campo autónomo, sino, más bien, como una idea o un modo de pensamiento (Rancière: 2000: 71; 2002: 205). Por ello es que, desde su trabajo en literatura en los años 90 del siglo pasado (1998), pasando por su conceptualización en torno a los regímenes del arte (2000: 26-45), hasta su trabajo sobre el cine $(2005 ; 2012)$, su problema ha consistido en cómo ejemplificar lo que llamó un régimen específico de comprensión artística bajo el sino de lo estético. Este régimen no sólo engloba al arte (que, para Rancière, precisamente, es disociado de su autonomía con la revolución estética), sino también a la política. Es a este haber que conceptos heredados tanto de la teoría del arte como de la filosofía política de los últimos doscientos años, tales como los de autonomía, modernismo, montaje o también los de revolución o pueblo, etc., deben ser reformulados. En efecto, ellos son insuficientes para pensar lo que ha significado este régimen específico de comprensión e identificación del arte y, con ello, las condiciones formales de cualquier política emancipatoria, las que -en términos del autor abordado-siempre serán estético-políticas.

De allí que en este texto nos proponemos revisar, en primer término, la comprensión de Rancière sobre su identificación de los regímenes del arte, principalmente en la confrontación que establece entre el régimen representativo y el estético. Luego, trataremos de definir este último régimen a partir de ciertas claves de lectura que situaremos en el fundamental concepto de sensorium, el que definiría la especificidad de lo estético, pero, además, describiremos cómo, a partir de este concepto, se explica lo que Rancière sostiene sobre una idea de hetereogeneidad que avala el concepto de montaje, el que, sin duda, es gravitante para lo que ha significado la modernidad artística.

\section{Regímenes de comprensión del arte}

La tematización que ha llevado a cabo Jacques Rancière en torno a los regímenes del arte ${ }^{1}$ no debe pensarse, en primer lugar, en relación con un campo determinado, a saber, el del arte. En segundo lugar, se debe tener la precaución de no

\footnotetext{
${ }^{1}$ Rancière ha identificado tres modos de comprensión de la obra de arte o, en otras palabras, tres regímenes de identificación de las prácticas artísticas en la tradición del pensamiento occidental: el régimen ético de las imágenes; el régimen representativo; y el régimen estético de las artes (Rancière, 2000: 26-45).
} 
reducir la noción de régimen a una mera comprensión histórica. Esto último, lo decimos en el entendido de que los regímenes parecieran ser secuenciales, puesto que uno se superpone al siguiente, pero ninguna de estas comprensiones discursivas se puede ubicar simplemente en un momento histórico determinado, dado que retornan y se cruzan entre ellas, coexistiendo la mayor parte de las veces en una estela temporal ${ }^{2}$. En tercer lugar, no obstante, lo más importante, en lo que Rancière denomina "régimen", se relaciona con una taxonomía que distingue aquello que es arte de aquello que no lo es, razón por la cual un régimen siempre es un régimen de comprensión o identificación.

En el primer régimen, que Rancière nomina como régimen ético de las imágenes, éstas son objeto siempre de dos preguntas: por un lado, sobre su verdad, en relación con su origen; por otro, sobre su destinación, es decir su uso, aquello que se hará con ellas y los efectos que provoquen (2000: 27). Es por este motivo que se ha considerado que este régimen no alcanza a ser comprensivo o identificatorio "puesto que no reconoce productos u operaciones del arte, y donde lo importante serían las formas de articulación entre un ethos y las imágenes" (Durán, 2013: 140). Si la pregunta por el arte es subsumida a una pregunta por el destino de las imágenes, se podría vislumbrar una identificación con prácticas cultuales que se vinculan a cierto umbral "ritualesco" o "chamánico", en una dimensión que se puede señalar, de forma provisoria, como "pre-artística". Es decir, las imágenes tienen tanto un poder de letargo como una potencia dispersiva, de manera que pueden formar un ethos que reúna a la comunidad, pero la comunidad, a su vez, puede dispersarse a partir del contacto con las imágenes. En este sentido, si dicho régimen se ubica bajo la égida del pensamiento platónico sobre el arte, también puede ser identificado en una dimensión cultual o religiosa, así como en expresiones de culturas no-occidentales y, contemporáneamente, en cierto cine al que podríamos atribuirle características "chamánicas" ${ }^{3}$.

\footnotetext{
${ }^{2}$ Con respecto al problema del concepto de "régimen de arte" y su vínculo con cierta periodización histórica, remitimos a lo observado por Oliver Davis, quien señala que, si Rancière pone el acento en la revolución que encarnaría la literatura, es a raíz de su más fuerte distancia con el historicismo. Por lo mismo no deja de ser interesante puntualizar que es en La parole muette donde de se establece la noción de "régimen del arte", ya que es justamente ahí, en ese texto, donde la oposición crucial entre representación y expresión se manifiesta para deslindar el régimen representativo y el estético, asumiéndose que pueden no obstante poseer una necesaria coexistencia (Rancière, 1998). En otras palabras, el concepto de régimen de arte se encuentra "desarraigado y arraigado a un análisis propiamente histórico" (Davis, 2010: 138).

${ }^{3}$ Alguien que ha tematizado profundamente la relación entre la potencia de las imágenes y cierto poder "chamánico" en ellas ha sido el cineasta chileno Raúl Ruiz, cuestión que se debería profundizar mucho más en otro lugar, pero que, por ahora, nos interesa mostrar brevemente, en el sentido de dotar de una especificidad de este régimen ético de las imágenes que formula Rancière, que a nuestro parecer no ha sido mayormente trabajado. Ruiz señala: "El chamán viaja en sueños, sobrevuela territorios lejanos, entra por
} 
Ahora bien, el anclaje para este régimen es la condena de los simulacros (pintura, poema, teatro), de los fantasmas que subvierten la idea o el referente. Sin embargo, para Rancière, no es que Platón condene el arte y lo subordine a la política, sino que más bien lo concibe como maneras de hacer, como prácticas en las cuales selecciona, divide artes verdaderas y artes falsas. Esta selección se relaciona con el afán pedagógico que tendrían las imágenes dentro de este régimen. El poema educa, forma, da cierta educación a los niños, es decir, contiene lo que Platón llama un ethos:

Las imágenes del poema dan a los niños y a los espectadores ciudadanos una cierta educación y se inscriben en el reparto de ocupaciones de la polis. Es en este sentido que hablo de régimen ético de las imágenes. En este régimen se trata de saber en qué medida la manera de ser de las imágenes conciernen al ethos, a la manera de ser de individuos y de colectividades. Y esta cuestión impide al "arte" individualizarse como tal (Rancière, 2000: 28)4.

El segundo régimen de comprensión -en el cual nos detendremos un poco más porque es fundamental para desarrollar el estatuto de lo estético-, Rancière lo define bajo el sino de lo representativo o poético de las artes, que se sostiene en dos nociones clásicas de la tradición filosófica occidental: mimesis y poiesis. Estos conceptos detallan dos caras de un mismo modelo afincado en el pensamiento aristotélico, tal como lo fija la Poética (Aristóteles, 1974). Se podría agrupar en dos momentos aquello que significa "representativo" dentro de este régimen: a) la obra de arte -en este caso, la tragedia- es un objeto que por naturaleza debe reconocerse en algo exterior a ella, a partir de la semejanza; b) la obra de arte es una acción, representa una acción, por lo cual debe estar sometida a un riguroso sistema de encadenamiento de partes, que, secuencialmente, brindarán un orga-

ventanas y chimeneas. Asiste a escenas que más tarde recordará. En ciertas ocasiones podrá volverse visible; en otras entrará en el cuerpo de animales salvajes o de recién nacidos (...). Yo me limito a decir que los viajes chamánicos sirven para ilustrar una forma de alejamiento muy curiosa: el desdoblamiento. Una operación compleja de la imaginación. Una práctica permanente del espectador de cine, siempre alerta a ese juego onírico que consiste en ver películas (...) todas las imágenes de una película determinada, son casos de desdoblamiento, viajes chamánicos mecanizados por la técnica cinematográfica, sólo entonces hay distanciamiento. Muchos distanciamientos, puros distanciamientos que nos fascinan con intensidades diversas. Y la dicotomía fascinación-distanciamiento desaparece. Sin embargo, el vértigo continúa cuando nos sentimos arrebatados por la sucesión de las imágenes y por la contemplación, y cuando descansamos del torbellino. La dicotomía ha sido reemplazada por otra, distinta, cuyo motor serán las intensidades que la suscitan. Diremos entonces, con los filósofos chinos, que 'respiramos' la película: que la hacemos entrar en nosotros y luego la hacemos salir de nuestro cuerpo imaginante" (Ruiz, 2013: 188-190).

${ }^{4}$ Las traducciones de Le Partage du sensible de Jacques Rancière son cotejadas con la traducción al castellano realizada por Cristóbal Durán, Helga Peralta, Camilo Rossel, Iván Trujillo y Francisco de Undurraga, en la edición de LOM (Rancière, 2009). 
nismo o una estructura. Ambas características se agruparían en una tercera, correspondiente a "la tekhné de la obra", que es la de ser un símil de la naturaleza, en tanto "potencia que encuentra su cumplimiento en el organismo viviente en general, y en el organismo humano en particular" (Rancière, 2002: 206). Sin embargo, se debe puntualizar que la mimesis es un principio pragmático y normativo que aísla, en las maneras de hacer, ciertas artes que ejecutan cosas específicas, es decir, imitaciones. Por lo tanto, la mimesis no somete las artes a la semejanza, puesto que no es un procedimiento o una característica de las obras del régimen representativo, sino más bien una distribución de las maneras de hacer, un régimen de visibilidad del arte dentro de un reparto general ${ }^{5}$.

Una arista importante de este régimen representativo de las artes tiene relación con la primacía de la palabra (el habla) por sobre lo visible. Es en este sentido que, por representativo, se puede entender lo siguiente: "la esencia de la palabra es hacer ver, ordenar lo visible desplegando un cuasi-visible en donde se fusionan dos operaciones: una operación de sustitución y una operación de manifestación" (Rancière, 2009b: 122-123). La representación es un despliegue ordenado de significaciones, pues mantiene una jerarquía de la palabra por sobre lo visible, es decir, lo que las palabras deben hacer es, precisamente, configurar lo visible, ordenarlo, repartirlo.

El régimen representativo del arte no es aquel en donde la tarea del arte es hacer semejanzas. Es el régimen en donde las semejanzas están sometidas a [una] triple obligación: un modelo de visibilidad de la palabra que organiza al mismo tiempo una cierta deducción de lo visible; un reglaje de las relaciones entre efectos de saber y efectos de pathos, comandado por la primacía de la "acción", emparentando el poema o el cuadro con una historia; un régimen de racionalidad propio de la ficción, que sustrae sus actos de palabra de los criterios de autenticidad y utilidad normales de las palabras y las imágenes para someterlas a criterios intrínsecos de verosimilitud y conveniencia. Esta separación entre la razón de las ficciones y la razón de los hechos empíricos es uno de los elementos esenciales del régimen representativo (Rancière, 2000: 128).

Es por esta razón que lo que definirá al poema o al cuadro como un ser racional es su subordinación a la racionalidad de la trama (el muthos), tal como lo define la Poética de Aristóteles. La operación que realiza el muthos es la de configurar un organismo con partes estructuradas "según un esquema de causalidad ideal el encadenamiento por necesidad o verosimilitud"- y que, de cierta manera, es semejanza y "forma de inteligibilidad de las acciones humanas" (56). La relación que se puede establecer entre el muthos como organismo de todo poema y la

\footnotetext{
${ }^{5}$ Este pasaje es aclarativo para este punto: "Llamo a este régimen poético en el sentido en que identifica a las artes al interior de una clasificación de las maneras de hacer, y por consiguiente define las maneras de hacer bien y de a preciar las imitaciones. Lo llamo representativo, en tanto que es la noción de representación o de mimesis la que organiza las maneras de hacer, de ver y de juzgar" (Rancière, 2000: 30).
} 
analogía es determinante para comprender lo que Rancière inscribe como régimen representativo de las artes. Esto, debido a que las palabras deben ordenar y configurar lo que es visible, procedimiento indisociable de lo que llamamos movimiento analógico, tal como lo concibió Aristóteles:

Entiendo por analogía el hecho de que el segundo término es al primero como el cuarto al tercero; entonces podrá usarse el cuarto en vez del segundo o el segundo en vez del cuarto; y a veces se añade aquello a lo que se refiere el término sustituido. Así, por ejemplo, la copa es a Dionisio como el escudo a Ares; llamará, pues, a la copa, 'escudo de Dionisio', y, al escudo, 'copa de Ares'. O bien, la vejez es a la vida como la tarde al día; llamará, pues, a la tarde 'vejez del día', o como Empédocles, a la vejez, 'tarde de la vida' u 'ocaso de la vida'. Pero hay casos de analogía que no tienen nombre, a pesar de lo cual se dirán de modo semejante; por ejemplo, emitir la semilla es 'sembrar' [sperein], pero la emisión de la luz desde el sol no tiene nombre [anônymon]; sin embargo, la relación con relación a la luz del sol es la misma [homoiôs] que sembrar en relación a la semilla, por lo cual se ha dicho 'sembrando luz de origen divino' (Aristóteles, 1974: 205-207 [1457b]).

Nos interesa precisar la existencia de una relación importante y necesaria entre, por una parte, el muthos y, por otra, lo que en Aristóteles vemos sobre el movimiento analógico, entablada como "medida común" de la tragedia y que implica una jerarquía del movimiento textual e inteligible, por sobre una potencia de la imagen que debe ser dialectizada y organizada ${ }^{6}$. Esta especie de conjuración la lleva a cabo el encadenamiento causal, que, como advertimos, es inherente al movimiento analógico del poema (de la imagen). Es precisamente esta subordinación de las palabras sobre lo visible como operación jerárquica del movimiento analógico, lo que, para Rancière, se libera en lo que denomina el régimen estético de las artes. Rancière sostiene que la ruptura que implica el régimen estético tiene, antes que todo, relación con la disociación del "modelo clásico de la autonomía de la obra" en su sentido plenamente aristotélico, es decir aquello que mayormente se establecía en "su dependencia mimética" (Rancière, 2002: 206).

El régimen estético de las artes puede ser interpretado, entonces, como interrupción de la organicidad en la cual se alojaba esta comprensión mimética y analógica de la obra. Es decir, lo estético se antepondrá directamente a lo representativo de las artes, pues éstas encontrarían, en dicho régimen, una especie de singularidad que las hará emanciparse de la pragmática y la taxonomía que proponía lo representativo. Es a este haber que deben repensarse fuertemente algunos vocablos que han identificado lo estético a la modernidad artística, así como

${ }^{6}$ El mismo Rancière en La fábula cinematográfica ha señalado que Aristóteles privilegiaba el muthos, la racionalidad de la trama por sobre la opsis, es decir, lo sensible y lo material de la tragedia. La opsis debe ser pensada como lo que está ante la vista, el espectáculo, la representación, la presencia, el aparecer, la visión, el sueño, las cosas en tanto objetos a la vista o en otras palabras a la imagen. (Rancière, 2005: 10-11) 
el papel que han jugado los modernismos artísticos junto con la idea de autonomía estética. De la misma manera es que se debería sopesar un concepto de montaje anclado más en una lógica tecnológica o industrial que en esta idea de pensamiento que se desprende de la ruptura estética.

\section{Heteronomía del sensorium estético}

Para especificar el dominio de lo que arguye en torno al régimen estético, Rancière debe fuertemente discutir cierto primado de lo que se ha denominado como "autonomía estética". La noción de autonomía, que se formula a la par de aquello que ha significado la "modernidad artística", sufre, según Rancière, de un gran equívoco. En efecto, no se trata de que el arte encuentre su propia especificidad, la que, de cierta manera, se ha pensado comúnmente a partir de la pintura moderna. La distancia que toma Rancière con las tesis modernistas en el arte se puede constatar en varios de sus textos, pero, sin lugar a dudas, esta distancia resulta más ejemplar en Le partage du sensible (2000: 26). Ahí, en efecto, se lleva a cabo un desplazamiento importante respecto de la tesis que ha pensado en la pintura, en su revolución y en el paradigma del descubrimiento de su superficie propia, es decir, en el paso desde la pintura tridimensional a la bidimensional que decreta el fin de la perspectiva y de la profundidad del cuadro o, en otras palabras, en la disolución de la representación pictórica. Críticos como Clement Greenberg (2006), notablemente, señalaron que el descubrimiento de la planitud en la superficie pictórica fue el momento en el cual la pintura encontró su propia definición. Para Rancière, sin embargo, esta confianza en lo "propio" de la pintura es sospechosa, en tanto "una superficie no es simplemente un conjunto de líneas geométricas (,) una superficie es una forma del reparto de lo sensible" (Rancière, 2000: 19; cursivas nuestras). Esta distancia que toma Rancière ante las tesis modernistas del arte se puede resumir de la siguiente manera: para pensar la relación entre arte y política o una política inherente a las prácticas artísticas, hay que identificarlas, primero que todo, bajo un régimen específico de comprensión del arte. Es que, para Rancière, el problema de enfocar la mirada básicamente en el soporte y el medio es que conduce a pensar más en la mediación que en el fin de cierta práctica, puesto que, por otro lado, no se puede sin más definir el trabajo a partir, simplemente, de los materiales que se usan. En efecto, el problema que vislumbra es que esta teoría de la pintura (la heredera de Greenberg) cae en una contradicción, al enfrentarse a la vieja dicotomía entre materia y forma, estando aún demasiado presa de la lógica que impera en el régimen representativo de las artes. En segundo lugar -y esto es lo más significativo, a nuestro entender-, Rancière señala que la tan mentada autonomía no era sino otro nombre para designar su más profunda heteronomía. Así, la identificación estética del arte es una desidentificación, deudora de una dispersión y una heterogeneidad general que 
articula inmanentemente este modo de pensamiento. En un repaso a ciertas escenas que constituyen esta clave de lectura del régimen estético, Rancière señala que esta clave de la heteronomía se puede ejemplificar del modo siguiente:

La revolución poética de Vico, al afirmar que Homero fue poeta porque no quiso ser poeta, porque expresó el saber que los hombres de su tiempo tenían sobre sí mismos de la única manera en la que podían expresarlo; prosigue con la afirmación balzacniana de que el gran poeta de la edad nueva no es un poeta sino el geólogo Cuvier, al igual que en la indiscernibilidad entre la escritura del Balzac gran novelista y del Balzac fabricante de Fisiologías con fines alimenticios; se prolonga en la búsqueda rimbaudiana del oro del poema nuevo en los estribillos bobos y las pinturas idiotas, o en el riesgo que la frase flaubertiana corre todo el tiempo de convertirse en una frase de Paul de Kock; en esos objetos no identificados que son el poema en prosa o el ensayo -por ejemplo, ese «ensayo» de Proust sobre Saint-Beuve que se transforma en la novela falsamente autobiográfica de En búsqueda del tiempo perdido-, acabando en la exposición de una teoría del libro contradictoria con su propio desarrollo (Rancière, 2011: 85).

La singularidad propia del régimen estético, ejemplificada en el párrafo recién expuesto, nos sirve para señalar este proceso de desidentificación que sufre el arte en lo que se ha llamado la modernidad estética. No existiría, para Rancière, una autonomía en las artes modernas, puesto que, justamente, la ruptura con lo representativo que hace irrumpir se relaciona con un desorden del todo inmanente a las prácticas artísticas; desorden graficado en un lazo, singular, entre lo que es arte y aquello que no lo es. El antídoto que la modernidad concibió contra este desorden que propicia la revolución estética fue el concepto de "modernismo" que revisamos hace un momento y que Clement Greenberg ayudó a cimentar. El modernismo, dice Rancière, "es el pensamiento del arte que busca la identificación estética del arte pero rechaza las formas de desidentificación en las que esta se efectúa (; es el) que busca la autonomía del arte" (2011: 86), pero de manera resistente a su más remarcada heteronomía. Es de este modo que la revolución modernista consistió en encontrar la propia especificidad del arte, su esencia pura. La ruptura con lo representativo, con la mimesis, significó para las teorías modernistas cierta liberación de la demanda mimética, en el sentido de que, en el anterior régimen, el arte debía encontrar un fin por fuera de sí, mientras que en la modernidad pareciera que ese fin está encarnado en sí mismo. El equívoco se consuma en este punto, puesto que ese fin guarda relación con la singular heterogeneidad del sensorium que las obras pertenecientes al régimen estético ponen en juego, más que con los poderes que cada disciplina desprende desde sus propias materialidades.

Así, si la literatura es lo ejemplar a la hora de definir el régimen estético -porque Rancière acredita que es ahí, en la literatura, donde "el desorden afectó, en primer lugar, al arte de escribir, antes de extender sus difuminaciones al campo de 
las Ilamadas artes plásticas y de las artes llamadas del espectáculo" (2011: 86)-, se debe constatar que alcanzó su modernidad, precisamente, al tomar una fuerte distancia respecto de lo que se entendía por las Bellas Letras, en el sentido de que ya no buscó comunicar, ni tampoco "(explotar) los puros poderes del lenguaje" (Ibíd. $)^{7}$. En otras palabras, si la literatura se liberó de cierto régimen, no fue para lograr su autonomía, sino, más bien, para asistir al encuentro de una identificación de pensamiento que, justamente, la desanudaba, la des-identificaba.

Si la noción de autonomía, como decíamos, es presa de un equívoco, es también porque no existe un espacio "propio del arte" dentro del régimen estético, pues las prácticas artísticas están siempre en un borde no-artístico y en una apertura permanente de sus modos expresivos. Es decir, para Rancière, lo esencial en el régimen estético de las artes es cómo las obras siempre están en una conexión, en un agenciamiento con otra cosa, pues esa otra cosa emancipa al arte mismo de un lugar en el cual estaba alojado clásicamente. Así, en Le partage du sensible, señala que este libro es más bien de una "interfaz" ${ }^{8}$ "interconexión", donde se

\footnotetext{
${ }^{7}$ Rancière, en un texto en comentario a Deleuze, dirá que "el principio de normatividad de lo representado" es parte central del régimen representativo de las artes, y específicamente de las "bellas letras". A partir de este principio "el tema representado dictaba los modos para representarlo, los géneros adecuados y los modos de expresión correspondientes. Dependiendo de si uno quería representar reyes o burgueses, pastores o animales, había que elegir formas poéticas que pertenecían a géneros diferentes y que implicaban leyes de composición diferentes también. Y había que utilizar lenguajes y tonos diferentes: de la unidad doble del estilo trágico en que la sirviente expresa sus pensamientos bajos en el estilo elevado de su ama, a la diversidad pintoresca de la novela en que cada quien habla el lenguaje que corresponde a su condición" (2012b: 56).

${ }^{8}$ Ha sido una lectura común la de sostener que Jacques Rancière es un pensador anti-técnico o anti-tecnológico. Al decir, por ejemplo, de Jean-Louis Déotte, existiría "una negación de la técnica en Rancière, como la había en Deleuze y en Lyotard y de una manera general en todos los fenomenólogos del arte" (2012: 13), donde se querría "reducir los regímenes del arte a la retórica para no tener que pensar su sustrato técnico" (77). En Le partage du sensible, Rancière es enfático en tomar una distancia ante lo que considera central en las tesis benjaminiana sobre el arte, que, de cierta manera, es la línea que un autor como Déotte sigue: "Existe posiblemente de antemano un equívoco al que debemos hacer frente, concerniente a la noción de 'artes mecánicas'. Por mi parte he relacionado un paradigma científico y otro estético. La tesis benjaminiana supone otra cosa, que me parece peligrosa: la deducción de las propiedades estéticas y políticas de un arte a partir de sus propiedades técnicas (....). Debemos, desde nuestro punto de vista, tomar las cosas a la inversa. Para que las artes mecánicas puedan dar visibilidad a las masas, o más bien al individuo anónimo, deben ser antes reconocidas como artes" (Rancière, 2000: 46-47). Rancière identifica, como veíamos, regímenes específicos de comprensión de la obra de arte que parecieran prescindir de cualquier sustrato técnico en su formulación; más bien, serían una discursividad que se posa sobre las diversas prácticas artísticas, ignorando las distinciones que existen en torno a distintos soportes o dispositivos, pero también en las diversas maneras de hacer. Por ejemplo, Déotte es muy claro en su distancia al señalar que, para Rancière, el segundo régimen de identificación de las artes, que es el régimen representativo, está anclado a un texto, a un discurso determinado, que sería la Poética de Aristóteles. La ambigüedad para Déotte de esta comprensión, es que no discierne distintos tonos epocales que dificultarían una fácil identificación de un régimen, así como las prácticas que agrupa. Si aquel régimen se ancla en la representación o en la mimesis, "la encontramos según
} 
produce la ruptura de "la doble política anterior, del régimen representativo" (Rancière, 2000: 21) que instalaba una dicotomía de dos planos, en el cual el arte debía representar otra cosa que a ella misma (mediante el procedimiento analógico, por ejemplo). Se separaba, por un lado, el mundo de las imitaciones artísticas y, por otro, el mundo de los intereses éticos y políticos, al tiempo que se postulaba que lo vivo estaba encarnado en la palabra y el acto, y que la escritura o la pintura, en tanto imágenes, sólo estaban encargadas de representarlo. Por el contrario, con la ruptura que significó el régimen estético, existío un triunfo de la página novelesca y del "entrelazamiento igualitario de las imágenes y los signos sobre la superficie pictórica" (Ibíd.). Esto significó, a su vez, un triunfo del ingreso de ciertos anónimos al gran arte o, en otras palabras, un triunfo del ingreso de la multiplicidad, de aquello que no tenía representación en las prácticas artísticas y no era propiedad de un arte, sino que cruzaba las distintas expresiones estéticas que la autonomía estética quería especificar:

La disyunción que separa al arte de lo bello, necesaria para su propia belleza, supo ser encontrada en todas partes por los novelistas de la comedia social y por los pintores de las nuevas diversiones urbanas y las salidas domingueras, abriéndose así el camino a nuevos artistas que, para realizar la unión del arte y el no arte, contaron con un arma inédita: el ojo mecánico que no sabía qué hacer con el arte o lo bello (Rancière, 2013: 56).

\section{El libre juego de las facultades}

A partir de lo que veníamos desarrollando en el anterior apartado, insistiríamos en señalar que la estética no es un pensamiento sobre la sensibilidad humana, ni tampoco una disciplina regional de la filosofía. La estética es un modo de pensamiento que se desprende de un sensorium paradójico y heterogéneo que permitirá identificar las cuestiones relativas al arte. Así es como en Cartas sobre la educación estética del hombre, de Friedrich Schiller (1963), -que, según Rancière, es el manifiesto de este régimen-, se define la ruptura con el régimen representativo, en tanto las artes, desde ahora, son comprendidas como un "modo de ser

Rancière, como el objetivo de la tragedia de Sófocles, como motivo en el arte del Renacimiento, pero al mismo tiempo en el corazón de la fábula cinematográfica en Hitchcock, l'istoria, y más ampliamente la fábula, no es un concepto discriminativo y no puede por lo mismo hacer época" (2002: 13). Lo que hace época, para Déotte, son los aparatos, mientras que para Rancière no habría una tematización más a fondo de los aparatos o dispositivos técnicos, pues pareciera intuir que no existe ningún tipo de configuración sensible que pre-exista a lo que él llama el reparto de lo sensible. Es decir, los aparatos técnicos/perceptivos son más bien un efecto del reparto de lugares, espacios, temporalidades o, en definitiva, de lo que Rancière llama lo sensible o lo común. Sin embargo, habría que puntualizar -a partir de la crítica que desliza Déotte de una anti-técnica en Rancière- que el reparto de lo sensible funciona por sobre todo como una operación tecnológica y que, a nuestro parecer, la técnica está pensada al interior del texto rancieriano pero bajo un tono distinto. Como por ejemplo en esta noción importantísima de la "interfaz". 
sensible". Con lo que rompe este modo es con un principio de armonía al cual estaba destinada la lógica representativa. Es, en cierta forma, lo que acontece con la Juno Ludovisi, referenciada en algunos lugares por Rancière (2011: 37-66; 2013: 36-37) como efigie que, por un lado, "alegoriza un estatuto del arte y su política" y, por otro, manifiesta su singular modo de ser sensible como "una "libre apariencia', cerrada sobre sí misma" (2011: 37). Como veníamos apuntando, la heteronomía de la obra estética es paradójica, en tanto se encuentra en una curvatura sobre sí, está cerrada en sí misma, motivo por el cual se confunde con lo propio de cada arte -su autonomía-, lo que vería Greenberg como característica primordial del modernismo. En otras palabras, no es el soporte, no es el médium material el que da identificación a la obra de arte, al permear sobre él su trabajo el artista, sino que ese medio es lo sensible en cuanto tal, en cuanto "sensorium particular, extranjero a las formas ordinarias de la experiencia sensible" (37).

De este modo es que la Juno Ludovisi con su “'libre apariencia'... manifiesta la característica esencial de la divinidad, su 'ociosidad' o 'indiferencia'" (38). La libre apariencia debe entenderse como aquello que la hace estar liberada de fines, de estar presa de un acuerdo discordante, sin ninguna voluntad que pudiera aunar esta extrema ociosidad. A fin de cuentas, lo que le interesa precisar a Rancière es cómo, para Schiller, la estatua griega propone para el espectador una posición distinta a la que tenía en el anterior régimen, es decir, a distancia de lo que contemplaba en tanto obra de arte, en el sentido de que la obra de arte representativa subordinaba la aiesthesis a las maneras de hacer de la poiesis. En efecto, acá, en el régimen estético, lo que propone la obra es un "libre juego":

La propiedad de ser una cosa del arte no se refiere aquí a una distinción entre los modos del hacer, sino a una distinción entre los modos de ser. Esto es lo que quiere decir "estética": la propiedad de ser arte en el régimen estético del arte ya no viene dada por criterios de perfección técnica, sino por la asignación a una cierta forma de aprehensión sensible (40; cursivas nuestras).

Si la estatua está formulada como una "apariencia libre", es en el sentido de anteponerse a las coordenadas que definían el régimen representativo de las artes. Como "forma sensible heterogénea" (41), no es simplemente una forma que reproduce lo sensible o las formas de la sensibilidad empíricas, puesto que no está en la posición de representar lo sensible, ni de encarnase como una forma activa sobre otra pasiva (el hilemorfismo clásico). La operación de la obra de arte estética sería más bien la de encontrarse instalada en una bifurcación entre "actividad y pasividad", entre "entendimiento y sensibilidad" (41).

Es de este modo que el concepto de juego, desde esa libre apariencia que definiría a la Juno Ludovisi y a la experiencia estética, es crucial para definir la especificidad de lo que Rancière comprende por estética. Su acepción, según lo hemos advertido, es una relectura del texto de Immanuel Kant, pasado por Schiller, pero 
actualizado contemporáneamente. A saber, el estado de juego propuesto por la Juno Ludovisi, tiene estricta relación con el libre juego de las facultades pensado por Kant en la Tercera crítica, así como para Schiller, con su idea de pensar la experiencia estética, en donde la noción de juego es preponderante. En Kant, el libre juego está vinculado a una suspensión de las propiedades de las facultades, tanto del entendimiento como de la sensibilidad: el entendimiento deja su poder determinante sobre los objetos sensibles, así como la sensibilidad deja su mera pasividad determinada. El libre juego de las facultades, para Rancière, "no es solamente una actividad sin objeto, es una actividad equivalente a una inactividad" (41). En otras palabras, es una especie de libertad que tendría la imaginación, la propiedad de "esquematizar sin concepto" (Kant, 1992: 226), lo que quiere decir que el objeto estético, la obra de arte en tanto libre apariencia, no es subsumible ni al entendimiento ni a la sensibilidad, sino que, más bien, es un modo de ser sensible que no puede ser reducido a las formas vulgares de la sensibilidad. Es en este punto que la pregunta deleuzeana, en su lectura de Kant, sobre cómo es producida esa libre concordancia entre las facultades es importante de asentar, pues Gilles Deleuze afirma que esa producción es trascendental, en tanto es "objeto de una génesis" (1963: 73). Esta producción genética, para Rancière, en sus términos, sería aquella de un singular modo de ser sensible.

[Los cruces entre el pensamiento estético de Jacques Rancière y cierta estética deleuzeana han sido poco trabajados, siendo que están bastante a la vista en el trabajo del primero. De hecho, la pertinencia de una estética deleuzeana viene planteada en un texto en homenaje a Deleuze que presentó Rancière luego de su muerte (2002). En aquel sugerente texto, Rancière enmarca a Deleuze en cierto destino de la estética, pero, a su vez, le plantea una pregunta a su pensamiento, en el sentido de si realmente el ejercicio de volver coherente a la obra de arte moderna, de hacer una lógica, es fiel a la nueva imagen del pensamiento que él se propuso construir. Como veníamos señalando, la ruptura de lo que Rancière señala en torno al régimen estético de las artes, subrayando cómo las obras, antes que todo, manifiestan su modo de ser sensible, es bastante cercana a la fórmula que Deleuze despliega en Différence et répétition, a partir de la definición que da sobre el empirismo trascendental, que, por cierto, está fuertemente enmarcado como una estética. Ahí, Deleuze dice lo siguiente: "el ser de lo sensible es el elemento fundamental por el cual emerge o germina lo sentido, es decir la sensibilidad misma" (1968: 182). Este ser de lo sensible, a su vez, es, antes que todo, una aprehensión que se escapa al orden de las facultades, es decir, precisamente aquello que acontece en la disyunción de este orden. Los análisis realizados por Rancière en torno a Deleuze (2002; 2005; 2012), parecieran olvidar esta fórmula, centrándose más bien en el Deleuze que trabajó más directamente el problema estético, es decir, el de los años 1980. Ahora bien, Rancière, en el texto que señalábamos, enmarca de lleno al pensamiento deleuzeano en el horizonte estético. 
La cuestión es problemática, en tanto Deleuze no tematizó directamente este problema, pero Rancière observa que sí "es posible situar el pensamiento de Deleuze en el destino de la estética como figura de pensamiento" (2002: 208). Esto es, básicamente, porque en Deleuze existe una fuerte crítica a la figuración y a la organicidad, cuestiones contra las cuales la estética en el sentido rancieriano se embiste. En definitiva, lo que Rancière nos devela es que la noción de sensación, que Deleuze (2002) trabaja en torno a la obra del pintor Francis Bacon, no es muy distinta de una concepción de la obra estrictamente derivada del régimen estético, según se puede rastrear en el sentido en que Deleuze señala a la sensación como una vía de escape de la figuración. Constantemente, lo figurativo, en la obra sobre Bacon, es homologada a lo representativo, es decir, a aquel régimen que Rancière contrapone al régimen estético de las artes, el que, decíamos, Deleuze consumaría precisamente a partir de esta noción de la sensación. En ese libro sobre Bacon, Deleuze apunta que la sensación opera en un nivel estrictamente material y carnal, al dirigirse hacia el sistema nervioso central y no hacia al cerebro, como podría hacerlo la forma abstracta (2002: 71). Por otro lado, en Bacon, la sensación es una deformación, una metamorfosis que opera no a un nivel primario, bajo una forma sensible determinada, sino que traspasa indiferenciando cualquier remisión de los sentidos a una organización de los mismos. En otras palabras, Deleuze señala que los niveles de sensación tienen "una manera de remitir a los otros, independientemente del objeto común representado. Entre un color, un sabor, un tacto, un olor, un ruido, un peso, habría una comunicación existencial que constituirá el momento 'pathico' (no representativo) de la sensación" (48). Es en este sentido que "pathico" define a la "pintura como la histeria"; lo que significa, en amplio sentido, que la obra se piensa como una operación de desobra. En palabras de Rancière, esto quiere decir volver enferma esta naturaleza que tiene como telos la autonomía orgánica" (2002: 208), o sea, introducir lo inorgánico, lo no representativo, lo heterogéneo, la multiplicidad, lo metamórfico; puras cualidades que Deleuze vería en la obra de Bacon como una resuelta lucha contra la figuración, contra el entendimiento de la obra como imitación de la naturaleza. Acá habría que volver a la lectura de Rancière, pues el régimen estético de las artes define una comprensión de la obra de arte de la siguiente manera:

Obra es un sensible separado de las conexiones ordinarias de lo sensible, vale en adelante como manifestación del espíritu, pero del espíritu en tanto que el mismo no se conoce. La estética nace como modo de pensamiento cuando la obra es subsumida bajo la categoría de un sensible heterogéneo, con la idea de que hay una zona de lo sensible que se separa de las leyes ordinarias del universo sensible y testimonia la presencia de otra potencia (209). 
En términos de Rancière, sí habría una estética deleuzeana, si concebimos que estética es un modo de pensamiento que se antepone frontalmente a la organicidad representativa de la obra o el poema.]

Habría que apuntar otra arista de la lectura kantiana embestida por Rancière, si consideramos que esta irrupción de la noción de lo bello sin concepto estaría graficada no sólo en la Juno Ludovisi, sino también en el torso mutilado de Níobe, que comenta a partir de un pasaje del historiador Winckelman. En efecto, este torso destruye "lo que es el núcleo de la lógica representativa, a saber, el modelo orgánico del todo con sus proporciones y sus simetrías" (Rancière, 2013: 24), a la vez que interrumpe las relaciones entre la sensibilidad y el entendimiento (25). Lo que está implicado en el análisis que realiza Rancière en la primera escena de Aiesthesis -libro en el cual, por cierto, elabora a partir de diversas escenas su obra más acabada en torno al régimen estético de las artes-, es, más bien, cómo la obra de arte ya no es bella en función de la armonía que los principios causales y orgánicos del antiguo régimen representativo consolidaban, es decir, en función de su subordinación a las coordenadas que se establecían entre el muthos y la analogía, como, por ejemplo, vimos más arriba. Así, se desplaza un movimiento que ya no es presa de una suma a partir de ciertas reglas para el arte, puesto que se trataría de lo contrario: de una sustracción de lo bello. Lo bello es sin concepto, es un modo singular de ser sensible, en términos kantianos, y, según palabras de Rancière, se establece ahora la radical "separación entre la bella forma y la obra de ciencia" (27). Es acá donde aparece una distinción entre el poder del genio para los antiguos y para los modernos. En el caso antiguo, como cifra del régimen representativo, el genio "era el complemento de naturaleza que devolvía las reglas y las competencias técnicas del arte a su fuente viva y les permitía así verificar su acuerdo con las afecciones del ser sensible en general" (28). Sin embargo, en la noción de genio que irrumpe con Kant, la inversión es importante en tanto la naturaleza "prescribe la regla no a la ciencia, sino al arte" (Kant, 1992: 217). Ya no existe correspondencia entre poeisis y aiesthesis, sino, más bien, un movimiento de sustracción que acontece a partir del poder de genio: lo bello acontece mientras más sustracción de lo inteligible o de reglas para el arte exista. En otras palabras, si se señala que los juicios estéticos no dependen del conocimiento, no están subordinados a una lógica argumentativa ni racional, siendo más bien lo que dicta la naturaleza en su despliegue, es decir, siendo objetos sin finalidad ni determinación, lo que opera en ellos, más que una adición armónica, es una sustracción, pues, tanta más sustracción haya, más belleza existirá. Es un genio que suspende las reglas sin ninguna producción de conocimiento.

El sensorio propio de la apreciación de lo bello ya no está regido por ninguna regla de conformidad con el sensorio de la fabricación del arte. Para franquear el abismo entre uno y otro hace falta, dirá Kant, el poder del genio y de las ideas estéticas. Pero ese genio ya no es el complemento que verifica el acuerdo entre las reglas del arte y las 
afecciones del ser sensible. Ahora es el azaroso puente tendido entre dos lógicas heterogéneas, la de los conceptos que el arte pone en acción y la de lo bello que carece de concepto. Es el poder, oscuro para el propio artista, de hacer algo distinto de lo que él hace, producir algo distinto de lo que quiere producir y, de tal modo, brindar al lector, al espectador o al oyente la posibilidad de reconocer y combinar de otra manera varias superficies sobre una sola, varias lenguas en una misma frase, varios cuerpos en un simple movimiento (Rancière, 2013: 28).

\section{Lo sin medida (el montaje)}

Lo que Rancière habría referenciado en el último pasaje citado no es sólo la consolidación de una mirada que establece una identificación singular de un nuevo régimen de las artes que tiene relación estricta con su conformación sensible y material, sino que también el develamiento de una práctica al interior misma de estas obras. Ahora bien, lo que queremos señalar es que, dentro de la irrupción que hace Rancière al acuñar la noción de régimen estético de las artes, expande una identificación que, para las teorías críticas del arte moderno serían extrañas. Es decir, cuando señala que "el libre juego" que pone en escena la Juno Ludovisi se encuentra en expresiones artísticas contemporáneas como las del arte relacional, la obra de Barnett Newman o las prácticas visuales de un Pierre Huyghe (2011: 30), lo que afirma es que no existe ningún tipo de ruptura, ni vanguardista ni, menos, post-vanguardistas. Sin ir más lejos, las escenas que están trabajadas en Aisthesis responden a esa filiación existente entre las pinturas de Murillo, el torso mutilado de Níobe, la pantomímica de Charles Chaplin y el arte decorativo. En todos ellos existiría la heteronomía radical de indistinguir el arte del no arte.

Ahora bien, en toda la configuración de este régimen, el papel del montaje es crucial de advertir, en tanto se le ha concebido tradicionalmente como un elemento a contrapelo de lo propiamente estético. El montaje, antes que todo, guarda una relación heteróclita con la temporalidad, en tanto el choque de diferentes temporalidades es lo que la práctica del montaje instala. Por ejemplo, alguien como Arnold Hauser ha señalado que el concepto de tiempo que se abre en la llamada modernidad, y que tiene su asidero más alto en las vanguardias artísticas, es fundamental para entender el paso desde una concepción representativa, mimética y analógica a una concepción de lo real desde el montaje ${ }^{9}$. El

\footnotetext{
${ }^{9}$ Referimos a la clásica definición que da Hauser sobre el montaje: "En esta nueva concepción del tiempo convergen casi todas las hebras del tejido que forman la materia del arte moderno: el abandono del argumento, del motivo artístico, la eliminación del héroe, el prescindir de la psicología [...] y, sobre todo, el montaje técnico y la mezcla de las formas espaciales y temporales [...] El nuevo concepto de tiempo, cuyo elemento básico es la simultaneidad, y cuya esencia consiste en la espacialización de los elementos temporales, en ningún otro género se expresa más impresionantemente que en este arte joven [...] Acontecimientos
} 
montaje, antes de ser una práctica artística y literaria, es una figuración de lo real, o una idea de pensamiento. Si habíamos señalado que la historia, entendida aristotélicamente como el muthos, era la configuradora de una medida común en la comprensión de un conjunto de acciones que daban cierta racionalidad al poema, habría que señalar, ahora, que lo que realiza el montaje es un común en dispersión, sin medida ni armonía, en tanto asistimos a una configuración de lo real desde una temporalidad heteróclita que da cuenta de tiempos simultáneos que chocan entre sí. En este sentido, para Rancière, el montaje no pervive a un nivel meramente industrial, que se coronaría como avatar perfecto en el aparato cinematográfico, sino, más bien, como una nueva configuración de lo real que toma distancia con aquella medida común que era el encadenamiento causal de las acciones perteneciente al régimen representativo del arte. Así, el montaje es el terreno de la disyunción de esa medida común, es la desvinculación de la clásica jerarquía de lo textual por sobre una función imaginante. Habría que volver a señalar que esta pérdida de la medida común no significa automáticamente la autonomía de cada una de las artes, pues, precisamente, las artes en el régimen estético se singularizan, pero no como tal o cual arte, sino más bien, en cuanto cada expresión u obra es una singularidad sin-medida, pero que siempre está en conexión con otra cosa que ella misma:

No se deriva que, en adelante, las palabras y las formas se separen, que algunas se consagren al arte de las palabras, mientras que otras trabajen los intervalos de tiempos, las superficies de color o los volúmenes de materia resistente. Tal vez se deduce todo lo contrario. Cuando el hilo de la historia, es decir, la medida común que reglaba la distancia entre el arte de unos y el de los otros, se encuentra desatado, ya no son simplemente las formas que se analogizan, sino que las materialidades se mezclan directamente (Rancière, 2009b: 59).

El montaje, entonces, es más una cuestión conceptual, un modo de comprensión de materialidades, de fibras, de tecnologías, por cierto, que fue más visible con la práctica del montaje literario de Pound, del montaje cubista o del montaje cinematográfico. El montaje tiene relación, en un principio, con lo que Rancière llama la gran parataxis, lógica que está vinculada a la literatura -como habíamos señalado más arriba- y, dentro de ella, sobre todo a Flaubert o a Zola, en donde se dan cita el desmoronamiento total de los encadenamientos racionales y lo que prima es lo puramente heterogéneo, la mezcla de diversas materialidades y temporalidades que entran en choque.

Un poco de polvo que brilla en el sol, una gota de nieve derretida cayendo sobre el moaré de un paraguas, una brizna de follaje en el hocico de un

paralelos y simultáneos pueden ser mostrados sucesivamente, y acontecimientos temporalmente distanciados, simultáneamente" (1992: 499). 
burro son los tropos de la materia que inventan amores igualando su razón a la gran ausencia de razón de las cosas (60).

Frente a esta contradicción característica del régimen estético de las artes, frente a este caos contradictorio, Rancière designa una operatoria común para lo sin común, que es la noción de "frase-imagen". Esta operación no significa, en primer término, la unión de lo verbal con lo visual, sino, más bien, cómo en lo estrictamente textual puede existir una función imaginante $y$, en la imagen, una potencia textual. Rancière desprende la noción estrictamente de un análisis que realiza de las Histoire(s) du cinéma, de Godard, en donde vería la puesta en juego del montaje moderno utilizando todos los recursos y operaciones, tanto a nivel de técnicas como a nivel de soporte, que el régimen estético de las artes ha llevado a cabo.

La operación de la frase-imagen, entonces, tiene relación con interrumpir la lógica que sostiene que el texto es representativo de una imagen cualquiera; lógica que, como hemos visto, pertenece al régimen representativo de las artes, puesto que decíamos que en él "la parte del texto era la del encadenamiento conceptual de las acciones, la parte de la imagen la del suplemento de presencia que le da carne y consistencia" (62). Ahora bien, si la frase-imagen interrumpe esta concatenación, es para instalar otro tipo de relación, definida por Rancière como "interfaz; en este caso, la de dos o más intencionalidades sensoriales y temporales que se dan cita en las imágenes, lo que pasaría estrictamente por un montaje. En otras palabras, si decíamos que en el régimen estético lo que existe es una medida sin común, esto pasa sobre todo por dar cuenta de una gran pasividad de lo caótico, de la gran parataxis, que, más allá de estar en una quietud, es la pasividad de todo aquello que está en constante movimiento y no cesa de relacionarse con lo otro, con lo diverso y heterogéneo (62):

Los escritores del siglo XIX que descubrieron, detrás de las historias, la fuerza desnuda de los remolinos de polvo, de la humedad opresiva, de las cascadas de mercancías o de las intensidades a lo loco también inventaron el montaje como medida de lo sinmedida o disciplina del caos. El ejemplo canónico es la escena de los Comicios de Madame Bovary, en la que la potencia de la frase-imagen se eleva entre los dos discursos vacíos del seductor profesional y del orador oficial, a la vez extraída de la torpeza ambiente en la que tanto uno como el otro se igualan, y sustraída a esta misma torpeza (64).

Quizás la obra de la modernidad artística que más consuma lo que Ranciere señala como régimen estético de las artes sería Histoire(s) du cinema, de Jean-Luc Godard, donde se habría realizado la siguiente operación: "Vincular sin fin, de la manera en que lo hace un plano de una película con el título o el diálogo de otra, una frase de una novela, un detalle de un cuadro, el estribillo de una canción, una fotografía de la actualidad o un mensaje publicitario, significa siempre hacer dos 
cosas al mismo tiempo: organizar un choque y construir un continuum" (75). Lo curioso de resaltar es que este procedimiento tiene el nombre de una lógica que, en principio, ha sido totalmente destruida, no por Godard, sino por los antecedentes de obras y firmas que lo preceden y que, de cierta manera, el cineasta trata de citar constantemente. Este nombre es el de "historia" o lo que señalábamos como "muthos", pues lo que hay es una "historia" del cine. La historia, acá, es totalmente anti-aristotélica, en el sentido de siempre contraponer dos cosas, dos imágenes, dos secuencias, dos frases absolutamente distintas. En otras palabras, es el lugar donde la frase-imagen se nos hace más manifiesta, pero también, a la vez, el lugar donde esas dos imágenes siempre remiten a otras imágenes que combaten, precisamente, al mundo convertido en imagen-cliché o en espectáculo. En definitiva, el procedimiento conlleva la instalación de una pragmática historiográfica que le debe todo al montaje ${ }^{10}$, es decir, de una comprensión estética de la obra o un modo de ser sensible, tomando en cuenta siempre que lo sensible es siempre el encuentro ante la heterogénesis y la multiplicidad.

\section{Referencias}

Aristóteles (1974). Poética, ed. trilingüe Valentín García Yebra. Madrid: Gredos.

Benjamin, Walter (2005). Obra de los pasajes, trad. Luis Fernández Castañeda, Fernando Guerrero, Isidro Herrera Baquero. Madrid: Akal.

Deleuze, Gilles (1963). La philosophie critique de Kant. París: PUF. (1968). Différence et répétition. París: PUF.

(2002). Francis Bacon. La lógica de la sensación. Madrid: Arena.

Déotte, Jean-Louis (2012). Qué es un aparato estético. Benjamin, Lyotard, Rancière. Santiago de Chile: Metales Pesados.

Durán, Cristóbal (2013). Patologías de la estética. Jacques Rancière y el aflojamiento del desastre. Actuel Marx/Intervenciones, (14). 137-153.

Greenberg, Clement (2006). La pintura moderna y otros ensayos. Madrid: Siruela.

\footnotetext{
10 "Un problema central en el materialismo histórico, que finalmente tendrá que ser abordado: ¿se tiene que adquirir forzosamente la comprensión marxista de la historia al precio de su captación plástica? o: ¿de qué modo es posible unir una mayor captación plástica con la realización del método marxista? La primera etapa de este camino será retomar para la historia el principio del montaje. Esto es, levantar las grandes construcciones con los elementos constructivos más pequeños. confeccionados con un perfil neto y cortante. Descubrir entonces en el análisis del pequeño momento singular, el cristal del acontecer toral. Así pues, romper con el naturalismo histórico vulgar. Captar la construcción de la historia en cuanto tal. En estructura de comentario. • Desechos de la historia." (Benjamin, 2005: 463)
} 
Felipe Larrea. Sobre el régimen estético de las artes en Jacques Rancière: heteronomía...

Hauser, Arnold (1993). Historia social de la literatura y el arte, 2, trad. A. Tovar y F. P. VarasReyes. Barcelona: Labor.

Kant, Immanuelle (1992). Crítica de la facultad de juzgar, trad. Pablo Oyarzún. Caracas: Monte Ávila.

Davis, Oliver (2010). Jacques Rancière. Cambridge: Polity Press.

Rancière, Jacques (1998). La parole muette. Essai sur les contradictions de la littérature. París: Hachette-Pluriel.

(2000). Le partage du sensible. Esthétique et politique. Paris: La Fabrique.

(2002). ¿Existe una estética deleuzeana? En: Alliez, Eric. Gilles Deleuze. Una vida filosófica. Santiago de Cali / Medellín: Sé cauto / Euphorion. 205-211.

(2005). La fábula cinematográfica. Reflexiones sobre la ficción en el cine, trad. Carles Roche. Barcelona: Paidós.

(2009). El reparto de lo sensible. Estética y política, trads. Cristóbal Durán, Helga Peralta, Camilo Rossel, Iván Trujillo y Francisco de Undurraga. Santiago de Chile: LOM.

Prometeo.

(2009b). El destino de las imágenes, trad. M. Gajdowski, Buenos Aires:

(2011). El malestar de la estética. trad. Miguel Petrecca, Lucía Vogelfang y Marcelo G. Burello. Buenos Aires: Capital Intelectual.

(2012). Deleuze, Bartleby y la fórmula literaria, trad. Ernesto Feuerhake. Papel Máquina (12). 55-75.

(2013). Aisthesis. Escenas del régimen estético de las artes, trad. Horacio Pons. Buenos Aires: Manantial.

Ruiz, Raúl (2013). Poéticas del cine, trad. Alan Pauls. Santiago de Chile: UDP.

Schiller, Friedrich (1963). Cartas sobre la educación estética del hombre, trad. Vicente Romano García. Madrid: Aguilar. 